\title{
Small Intestinal Anastomotic Leak, CTCAE
}

National Cancer Institute

\section{Source}

National Cancer Institute. Small Intestinal Anastomotic Leak, CTCAE. NCI Thesaurus. Code C143841.

A finding of leakage due to breakdown of an anastomosis (surgical connection of two separate anatomic structures) in the small bowel. 